\title{
ANÁLISE DA PERCEPÇÃO AMBIENTAL DE ALUNOS DO ENSINO BÁSICO ACERCA DA QUALIDADE DA ÁGUA
}

\author{
ANALYSIS OF THE ENVIRONMENTAL PERCEPTION OF BASIC EDUCATION \\ STUDENTS ABOUT WATER QUALITY
}

\author{
ANÁLISIS DE LA PERCEPCIÓN AMBIENTAL DE ESTUDIANTES DE EDUCACIÓN \\ BÁSICA SOBRE LA CALIDAD DEL AGUA
}

\author{
Carmem Sara Pinheiro de Oliveira ${ }^{1}$ \\ Gabriel Contini ${ }^{2}$ \\ Niltom Vieira Junior ${ }^{3}$
}

\begin{abstract}
Resumo
A qualidade da água é uma necessidade universal, que exige atenção por parte das autoridades sanitárias e consumidores em geral. Os problemas ambientais, especialmente os relacionados a este recurso, têm se acentuado, de acordo com o crescimento populacional. Deste modo, intervenções, sobretudo as destinadas a formar um pensamento crítico na população, se fazem necessárias, para se obter resultados significativos, entre elas a educação ambiental. A escola é o principal agente para esclarecer, produzir consciência e formar comportamento cidadão participativo nas questões ambientais. Para isso, é necessário medir o conhecimento prévio dos alunos a respeito do assunto. Então, esta pesquisa visou conhecer, por meio da aplicação de um questionário, a visão de discentes do $7^{\circ}$ ano do Ensino Básico Fundamental de uma escola pública situada no município de Natal, Rio Grande do Norte, acerca de inúmeras situações relacionadas à qualidade de água, que dizem respeito à sociedade, à saúde e ao meio ambiente. Os resultados mostram que, apesar de não existir uma disciplina específica para a educação ambiental, os conhecimentos empíricos dos alunos sobre o tema são mais adequados que os conteúdos abordados dentro da disciplina Ciências, que necessitariam de outra abordagem, mais ativa e efetiva, pois o conhecimento formal nesta área se apresentou insuficiente.
\end{abstract}

Palavras-chave: Ciências. Educação ambiental. Ensino fundamental. Qualidade da água.

\begin{abstract}
Water quality is a universal need, which requires attention from health authorities and consumers in general. Environmental problems, especially those related to this resource, have been accentuated, according to population growth. Thus, interventions, especially those aimed at forming critical thinking in the population, are necessary to obtain significant results, including environmental education. The school is the primary agent to clarify, raise awareness and form participatory citizen behavior on environmental issues. Therefore, it is necessary to measure the students' prior knowledge on the subject. Hence, this research aimed to know, through a questionnaire, the view of 7th grade students of a public basic education school located in the city of Natal, Rio Grande do Norte, about numerous situations related to water quality, which concern society, health, and the environment. The results show that, although there is no specific subject for environmental education, students' empirical knowledge on the topic is more appropriate than the content covered within the Science subject, which would need another, more active and effective approach, as the formal knowledge in this area proved to be insufficient.
\end{abstract}

Keywords: Sciences. Environmental education. Elementary school. Water quality

Resumen

\footnotetext{
1 Pós-graduanda pelo Programa de Pós-graduação em Docência do Instituto Federal de Minas Gerais - Campus Arcos. Doutoranda pelo Programa de Pós-graduação em Desenvolvimento e Meio Ambiente da Universidade Federal do Rio Grande do Norte - Centro de Biociências. Professora do Estado do Rio Grande do Norte. E-mail: carmemspoliveira@gmail.com.

2 Pós-graduando pelo Programa de Pós-graduação em Docência do Instituto Federal de Minas Gerais - Campus Arcos. Email: continigabriel@gmail.com.

3 Professor Doutor do Instituto Federal de Minas Gerais - Campus Arcos. E-mail: niltom.vieira@ifmg.edu.br.
} 
La calidad del agua es una necesidad universal, que requiere la atención de las autoridades sanitarias y de los consumidores en general. Los problemas ambientales, especialmente los relacionados con este recurso, se han acentuado, de acuerdo con el crecimiento de la población. Por lo tanto, intervenciones, especialmente las destinadas a formar un pensamiento crítico en la población, son necesarias, para que se logren resultados significativos, entre ellas la educación ambiental. La escuela es el principal agente para aclarar, generar conciencia y formar comportamiento ciudadano participativo en las cuestiones ambientales. Para ello, es necesario medir los conocimientos previos de los estudiantes sobre el tema. Entonces, esta investigación tuvo como objetivo conocer, mediante la aplicación de un cuestionario, la opinión de los estudiantes del séptimo año de educación básica de una escuela pública ubicada en la ciudad de Natal, Rio Grande do Norte, sobre numerosas situaciones relacionadas con la calidad del agua, que afectan a la sociedad, a la salud y al medioambiente. Los resultados muestran que, aunque no exista una disciplina específica para la educación ambiental, el conocimiento empírico de los estudiantes sobre el tema es más adecuado que los contenidos cubiertos por la disciplina Ciencias, que necesitarían un enfoque más activo y efectivo, porque el conocimiento formal en esta área demostró ser insuficiente.

Palabras-clave: Ciencias. Educación ambiental. Educación básica. Calidad del agua.

\section{Introdução}

Em 1924, Oparin propôs que a vida no planeta Terra se originou na água a partir de moléculas orgânicas. Dessa forma, é possível associar a sujeição dos seres vivos à água, e afirmar que a quantidade e a qualidade deste recurso no planeta sempre foram essenciais para manter os ciclos de vida, a biodiversidade dos organismos e, sobretudo, a sobrevivência da espécie humana (apud REBOUÇAS, 2002).

Historicamente, a água é de extrema importância para o desenvolvimento cultural e econômico, desde as colonizações às margens de rios e o batismo nas religiões, até a sua utilização para grandes produções de alimentos e desenvolvimento de equipamentos de última geração. Este vasto emprego da água lhe atribui um valor inestimável para a sociedade; entretanto, o desenvolvimento econômico e a complexidade da organização das sociedades humanas produziram inúmeras alterações no ciclo hidrológico e na qualidade deste recurso (TUNDISI, 2003, 2006).

Rosen (1958) já ressaltava que os principais problemas de saúde enfrentados pela humanidade têm relação com o controle e a melhoria do ambiente físico (saneamento) e a quantidade e qualidade da água disponível para a população. À vista disso, falar da relevância dos conhecimentos sobre a água, em suas diversas dimensões, é ajudar à sua preservação e propor utilização sustentável deste recurso, pois, embasado em uma multiplicidade de aspectos — sociais, econômicos, culturais, tecnológicos e ambientais — nos deparamos com a má gestão dos recursos hídricos disponíveis e a falta de saneamento básico, retratados na pobreza (JACOBI, 2005).

$\mathrm{Na}$ busca da preservação dos recursos hídricos foi criada pelo governo a lei 12.651 (BRASIL, 2012), em cujo artigo $1^{\circ}$, parágrafo I, tem-se como dever a preservação da vegetação nativa, bem como a biodiversidade do solo e dos recursos hídricos, para o bem da geração 
presente e das futuras; o parágrafo $\mathrm{V}$ fomenta a pesquisa científica e tecnológica, na busca do uso sustentável do solo e da água, a sua preservação e conservação.

Contini, Pinto e Barros (2017) destacam que, apesar de serem esses recursos protegidos por leis, sabe-se que o desrespeito à legislação é generalizado em todo o país. A qualidade da água é uma necessidade universal, que exige atenção por parte das autoridades sanitárias e consumidores em geral, principalmente no que se refere aos mananciais - como poços, minas e nascentes -, destinados ao consumo humano. Apesar da evidente necessidade de proteção destes mananciais, esses ambientes têm sido degradados, principalmente em espaços urbanos, onde são canalizados para a utilização humana, sem um devido estudo de gestão.

Dessa maneira, uma forma de controle da qualidade da água é a conscientização da população por meio da educação ambiental, um ramo da educação cujo objetivo é a disseminação do conhecimento sobre o meio ambiente, previsto no Art. 225 da Constituição Federal (BRASIL, 1988), para todos os níveis de ensino, com proposta de conscientização pública para a preservação do meio ambiente.

Duarte et al. (2012) esclarecem que:

[...] a Educação Ambiental tornou-se lei em 27 de Abril de 1995 (BRASIL, 1995). A Lei N ${ }^{\circ} 9.793$ - Lei da Educação Ambiental - em seu Art. $1^{\circ}$ afirma: "Processo em que se busca despertar a preocupação individual e coletiva para a questão ambiental, garantindo o acesso à informação em linguagem adequada, contribuindo para o desenvolvimento de uma consciência crítica e estimulando o enfrentamento das questões ambientais e sociais" Art. $2^{\circ}$ "A educação ambiental é um componente essencial e permanente da educação nacional, devendo estar presente, de forma articulada, em todos os níveis e modalidades do processo educativo, em caráter formal e não formal".

Ainda afirma que no Brasil a educação ambiental não se restringe à proteção e uso sustentável dos recursos naturais; exibe uma concepção mais ampla, agregando uma noção de sociedades sustentáveis (DUARTE et al., 2012).

A Secretaria de Educação Fundamental (BRASIL, 1997) trata a educação ambiental como um tema transversal, de acordo com os Parâmetros Curriculares Nacionais; assume-a como um tema interdisciplinar que abrange questões sociais, com intenção de levar aprendizagem e reflexão aos alunos. Assim, a educação ambiental, aplicada a crianças em formação, implicará na formação de indivíduos preparados e participativos, para lidar com problemas ambientais da atualidade e exercer seu direito à cidadania.

Deste modo, o presente estudo justifica-se pela necessidade de se entender a visão de discentes do Ensino Básico Fundamental acerca de inúmeras situações relacionadas à qualidade da água, que dizem respeito à sociedade, à saúde e ao meio ambiente. Isso decorre devido aos 
problemas de crise hídrica que vêm sendo destacados no mundo, assim como à falta de uma educação ambiental específica nas escolas para promover um melhor entendimento sobre a temática. Esperou-se, além de verificar as concepções preestabelecidas, analisar de maneira contextualizada como a educação ambiental pode ser uma importante ferramenta para o desenvolvimento social.

Diante do exposto, o presente artigo propõe uma análise das percepções de discentes acerca da qualidade da água, bem como compreender o papel da educação ambiental para a construção de sólidos conceitos acerca da temática proposta no estudo.

\section{Metodologia}

Este estudo desenvolveu-se, a princípio, com 140 alunos distribuídos em cinco turmas do $7^{\circ}$ ano do Ensino Fundamental II, durante o turno matutino de uma escola pública, situada no município de Natal, Rio Grande do Norte. Os dados foram coletados em novembro de 2019, mediante autorização da diretoria da instituição de ensino. A escolha da turma se deu em função de esta série já ter trabalhado assuntos relativos à água e meio ambiente, sendo assim mais adequado inferir a percepção dos alunos.

Antes da aplicação dos questionários foi enviado para os pais ou responsáveis um Termo de Consentimento Livre e Esclarecido (TCLE), explicando de maneira clara e objetiva as informações necessárias acerca da pesquisa. O condicionamento da leitura e assinatura (entregues) do TCLE pelos responsáveis legais pelo aluno foi o primeiro critério de exclusão aplicado no trabalho. O segundo critério se deu em função do não preenchimento completo do questionário fornecido por parte do alunado. Desta maneira, totalizamos um n amostral de 118 participantes, sendo 22 excluídos posteriormente, ao início da pesquisa, em função do segundo critério de exclusão.

Para avaliar a concepção dos estudantes acerca da temática qualidade da água, foram aplicados questionários estruturados com 18 perguntas, tendo em vista que as questões de múltipla escolha possibilitam a consideração de características, experiências e decisões. A aplicação só foi efetuada após a explicação em sala de aula sobre a importância do estudo e conteúdo, contudo, sem interferência da professora, de modo a evitar tendências nas respostas. As questões fechadas versavam acerca de cinco frentes de análise: perfil individual dos discentes, entendimento sobre a qualidade da água, abastecimento hídrico, contaminações das águas de uso e conscientização ambiental. O questionário apresentou metodologia de percepção ambiental semelhante à utilizada por Rêgo e Lima (2018). 
Esta pesquisa é do tipo descritiva com abordagem quantitativa. Os resultados foram expressos em números inteiros e percentual, sendo os dados registrados em planilha eletrônica no software Microsoft Excel ${ }^{\circledR} 2016$ e analisados a partir do mesmo.

\section{Resultados e discussão}

Entre os discentes entrevistados, no tocante ao perfil, pôde-se observar que a maioria esteve composta por alunos do sexo feminino, correspondente a 57,63\% $(n=68)$, enquanto o sexo masculino apresentou 42,37\% $(n=50)$. As idades variaram de 11 a 17 anos, sendo 13 anos a predominante, com 50,00\% ( $\mathrm{n}=59)$; a segunda de maior destaque foi 12 anos, 26,27\% ( $\mathrm{n}=$ 31); seguida pelas demais idades, 14 anos 15,25\% $(\mathrm{n}=18) ; 15$ anos 5,93\% $(\mathrm{n}=7) ; 11,16$ e 17 anos, cada uma com $0,85 \%(n=1)$. O bairro apontado como sendo a residência de 20,34\% ( $\mathrm{n}$ =24) é o Alecrim, local onde se encontra a escola; o segundo bairro de maior destaque agrupa alunos oriundos de municípios pertencentes ao interior do estado, que foram considerados em uma única categoria, 'Interior', com 11,86\% ( $\mathrm{n}=14)$; já o terceiro, com 9,32\% ( $\mathrm{n}=11)$, pertence ao bairro de Felipe Camarão; os demais 27 bairros tiveram percentual menos relevante.

Os sujeitos foram indagados sobre conhecer os parâmetros básicos de análise para qualidade de água; nota-se que a maioria afirmou que $\operatorname{sim}(46,61 \% ; \mathrm{n}=55)$, todavia o número de alunos que não conhece ou que se mostrou inseguro na resposta foi superior a esse percentual, como pode ser visto na Tabela 1. A maioria concorda que uma água limpa (transparente) é sempre de boa qualidade $(62,71 \%$; $n=74)$. Essa reposta nos indica que, no ensino público, fica evidente a necessidade de inserção de novas metodologias ativas e experimentais no ensino de ciências, biologia ou química, que sejam capazes de promover uma aprendizagem efetiva. Neste contexto, Oliveira (2010) destaca que atividades experimentais propiciam a capacidade de se trabalhar em grupo, o que pode contribuir para um aprimoramento de várias habilidades e competências, como a repartição de ideias e abordagens para solução de problemas.

Essa afirmação é válida também para a pergunta seguinte, acerca da qualidade da água que chega às residências ser de boa qualidade. $72,88 \%(n=86)$ afirma que sim. Sobre o que uma água de boa qualidade para o consumo humano não pode conter, os alunos ficaram livres para marcarem mais de uma assertiva; a maioria $(n=87)$ atentou para animais (bichos) que não

poderiam estar na água, assim como cor $(\mathrm{n}=79)$, corroborando os resultados encontrados nas perguntas anteriores no que diz respeito a conhecimento teórico insuficiente. Para os entrevistados, uma água transparente é tida como boa sem levar em consideração os demais 
critérios de qualidade, pela falta de conhecimento integrado, adequado e mais denso. Loureiro (1997) ainda destaca que o contexto interdisciplinar da educação ambiental é abordado de forma frágil nos livros didáticos do ensino básico, onde a temática da água, importante elemento da natureza e com capacidade de transformação social, tem sido pouco abordada.

Tabela 1: Distribuição de alunos participantes da pesquisa acerca da qualidade da água.

\begin{tabular}{|c|c|c|c|}
\hline & & $\mathbf{N}$ & $\%$ \\
\hline \multirow{3}{*}{$\begin{array}{l}\text { Você conhece os parâmetros } \\
\text { básicos de qualidade da água? }\end{array}$} & Sim & 55 & 46,61 \\
\hline & Não & 30 & 27,97 \\
\hline & Não sei & 33 & 25,42 \\
\hline \multirow{3}{*}{$\begin{array}{l}\text { Uma água limpa (cristalina) é } \\
\text { sempre de boa qualidade? }\end{array}$} & Sim & 74 & 62,71 \\
\hline & Não & 30 & 25,42 \\
\hline & Não sei & 14 & 11,86 \\
\hline \multirow{3}{*}{$\begin{array}{l}\text { Você acha que a qualidade da água } \\
\text { que chega em sua casa é boa? }\end{array}$} & Sim & 86 & 72,88 \\
\hline & Não & 17 & 14,41 \\
\hline & Não sei & 15 & 12,71 \\
\hline \multirow{5}{*}{$\begin{array}{l}\text { O que uma água boa para o } \\
\text { consumo humano não pode conter? }\end{array}$} & Cor & 79 & 25,57 \\
\hline & Cheiro & 71 & 22,98 \\
\hline & Sabor & 65 & 21,04 \\
\hline & Bichos & 87 & 28,16 \\
\hline & Não sei & 7 & 2,27 \\
\hline
\end{tabular}

Fonte: Autoria própria (2019).

Os resultados reportaram que 70,34\% $(\mathrm{n}=83)$ dos educandos sabe de onde vem a água que abastece suas residências, assim como a grande maioria $(66,10 \%$; $n=78)$ já visualizou vazamento de água em sua rua. Quando questionados sobre o dever de garantir uma boa qualidade das águas, um percentual significativo de 78,81\% afirmou que isso é um dever de todos, demonstrando uma certa conscientização, ainda que rudimentar (Tabela 2). Diante da complexidade dos problemas globais, isso nos mostra a importância de se discutir acerca de temáticas socioambientais no âmbito escolar, de modo a possibilitar uma visão mais crítica perante as necessidades ambientais (VIEGAS; NEIMAN, 2015).

Tabela 2: Distribuição de alunos participantes da pesquisa acerca do abastecimento hídrico.

\begin{tabular}{lccc}
\hline & & $\mathbf{N}$ & \% \\
\hline Você sabe de onde vem a água que & Sim & 83 & 70,34 \\
\cline { 2 - 4 } abastece sua casa? & Não & 35 & 29,66 \\
\hline Na sua rua, você já observou & Sim & 78 & 66,10 \\
\cline { 2 - 4 } vazamento de água? & Não & 40 & 33,90 \\
\hline \multirow{2}{*}{$\begin{array}{l}\text { De quem é o dever de garantir uma } \\
\text { boa qualidade das águas? }\end{array}$} & População & 4 & 3,39 \\
\cline { 2 - 4 } & Todos & 93 & 78,81 \\
\cline { 2 - 4 } & Governo & 21 & 17,80 \\
\hline
\end{tabular}

Fonte: Autoria própria (2019). 
Segundo o Instituto Trata Brasil (2012), as doenças de veiculação hídrica podem ser disseminadas mediante vetores, contato ou ingestão de águas contaminadas. Uma boa parte dos alunos $(88,14 \% ; \mathrm{n}=104)$ possui o entendimento de que a contaminação dos recursos hídricos é passível de produzir doenças nos seres humanos, podendo essa contaminação ser causada pela ingestão $(99,15 \% ; n=117)$ ou pelo contato cutâneo $(82,20 \% ; n=97)$ (Tabela 3).

Tabela 3: Distribuição de alunos participantes da pesquisa acerca das contaminações das águas de uso.

\begin{tabular}{lccc}
\hline & & $\mathbf{N}$ & $\mathbf{\%}$ \\
\hline A contaminação dos rios, açudes, & Sim & 104 & 88,14 \\
\cline { 2 - 4 } $\begin{array}{l}\text { poços e reservatórios, pode causar } \\
\text { doenças? }\end{array}$ & Não & 2 & 1,69 \\
\cline { 2 - 4 } $\begin{array}{l}\text { Ingerir água contaminada pode } \\
\text { causar alguma doença? }\end{array}$ & Sim & 12 & 10,17 \\
\cline { 2 - 4 } & Não & 1 & 99,15 \\
\cline { 2 - 4 } $\begin{array}{l}\text { Tomar banho com água } \\
\text { contaminada pode causar alguma } \\
\text { doença? }\end{array}$ & Sim & 0 & 0,85 \\
\cline { 2 - 4 } & Não & 3 & 0 \\
\cline { 2 - 4 } & Não sei & 18 & 15,25 \\
\hline
\end{tabular}

Fonte: Autoria própria (2019).

Neste contexto, entender quem pode promover tais contaminações aos mananciais hídricos é fundamental para o desenvolvimento do pensamento crítico dos alunos; os responsáveis por essa contaminação, de acordo com os alunos, são o ser humano $(41,60 \%)$ e as indústrias (30,67\%), apontados no gráfico 1. Em sua grande maioria, os impactos ambientais são promovidos por ações antrópicas, sendo necessário o entendimento do problema para que posteriormente possamos promover uma mudança no comportamento da sociedade (SPINELLI et al., 2016). Essas mudanças se tornam mais significativas quando são mediadas pela formação de base, ou seja, nas escolas, para que possamos mitigar tais impactos.

Gráfico 1: Percentual dos alunos participantes da pesquisa acerca de quem pode contaminar recursos hídricos.

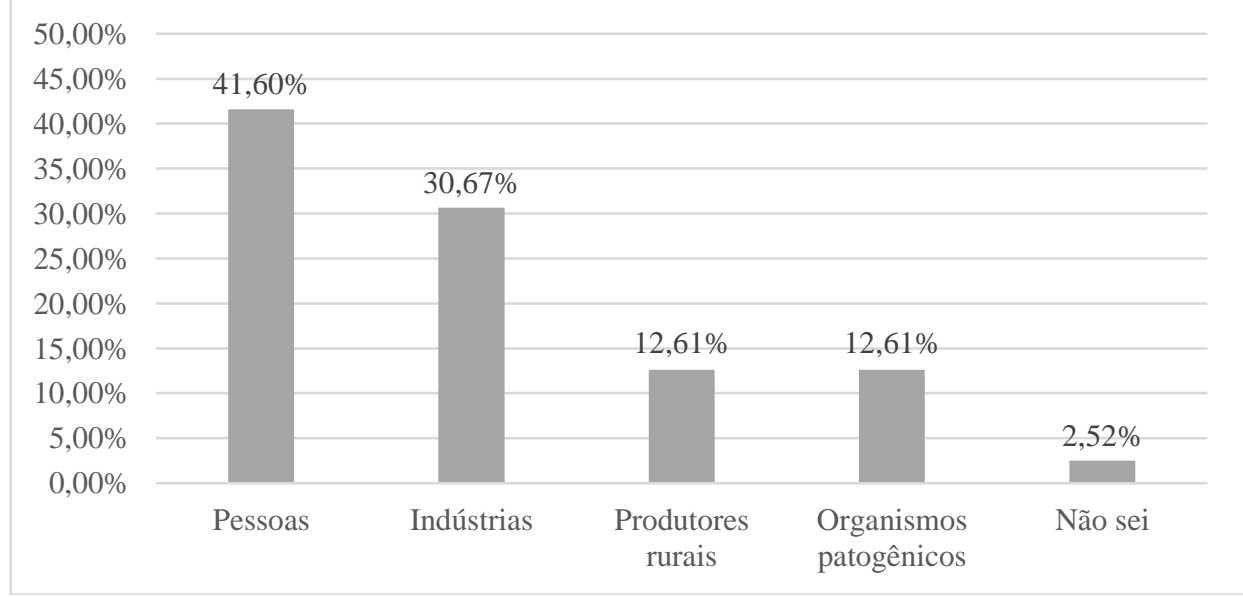

Fonte: Autoria própria (2019). 
O gráfico 2 indaga sobre os tipos de doenças que uma água contaminada pode causar ao indivíduo; aparecem as doenças de pele $(28,05 \%)$, diarreia $(22,77 \%)$ e verminose $(21,12 \%)$ com maior destaque para os discentes. Diversas enfermidades estão correlacionadas com o contato direto ou indireto de águas contaminadas (CAMARGO et al., 2017), contudo os alunos destacaram aquelas em que a proximidade com a população é mais evidenciada, reforçando a necessidade de investimentos mais interdisciplinares e metodologias ativas no ensino de ciências.

Gráfico 2: Percentual dos alunos participantes da pesquisa acerca de quais doenças uma água contaminada pode causar.

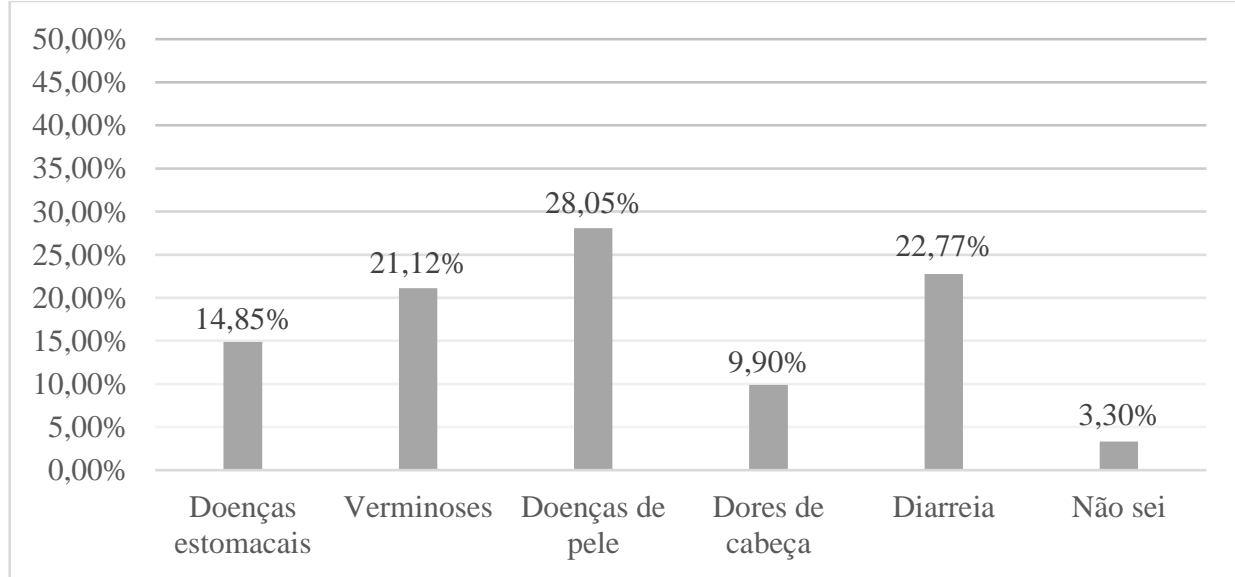

Fonte: Autoria própria (2019).

Os sujeitos amostrais apontaram que uma boa consciência ambiental por parte dos indivíduos auxilia na preservação da qualidade dos recursos hídricos $(86,44 \% ; \mathrm{n}=102)$, bem como na disponibilidade quantitativa destes recursos $(90,68 \% ; \mathrm{n}=107)$, como pode ser analisado na tabela 4. Para fomentar essa consciência, 94,92\% dos alunos entende ser necessária uma disciplina de educação ambiental para que temáticas como essa possam ser elucidadas de maneira satisfatória e contínua. Piccoli e seus colaboradores (2016) afirmam que o debate entre a educação e o meio ambiente é mediado em virtude da grande problematização em volta da crise ambiental.

Tabela 4: Distribuição de alunos participantes da pesquisa acerca da conscientização ambiental.

\begin{tabular}{lccc}
\hline & & $\mathbf{N}$ & \% \\
\hline Ter uma boa consciência ambiental & Sim & 102 & 86,44 \\
\cline { 2 - 4 } ajuda a preservar a qualidade da & Não & 1 & 0,85 \\
\cline { 2 - 4 } água? & Não sei & 15 & 12,71 \\
\hline Ter uma boa consciência ambiental & Sim & 107 & 90,68 \\
\cline { 2 - 4 } ajuda a preservar a quantidade da & Não & 4 & 3,39 \\
\cline { 2 - 4 } água? & Não sei & 7 & 5,93 \\
\hline Todas as escolas deveriam ter uma & Sim & 112 & 94,92 \\
\cline { 2 - 4 } disciplina de Educação Ambiental? & Não & 6 & 5,08 \\
\hline
\end{tabular}

Fonte: Autoria própria (2019). 
$\mathrm{Na}$ atualidade diversos fatores configuram-se em riscos ambientais para a sociedade. A disponibilidade de água de má qualidade e a falta de entendimento acerca das múltiplas faces da conscientização ambiental são problemas característicos, que podem ser mudados em função de atitudes sustentáveis, mediante a inserção da educação ambiental no contexto escolar. Esse mecanismo integrador das ciências da natureza é capaz de alterar o panorama social atual e viabilizar a preservação dos recursos naturais. Jacobi (2005) aponta que o desafio da educação ambiental se encontra relacionado a uma formação da cidadania ambiental, tendo em vista o despertar do interesse pelas questões ambientais, especialmente no tocante à manutenção da qualidade da água.

O estudo da percepção ambiental é de notória relevância para que possamos compreender as amplas relações entre o homem e o meio ambiente, suas condutas, expectativas, julgamentos, entre outras características, visando sempre a harmonia e a manutenção do meio e do ser humano. Neste cenário, a abordagem de temas relacionados à educação ambiental assume ampla responsabilidade social, objetivando a percepção da cidadania e a formação da consciência ambiental nos diferentes sujeitos. Em especial, destaca-se aqui a temática da água, tão relevante para a manutenção da vida de muitos seres (ANTUNES et al., 2014).

\section{Conclusão}

O objetivo principal deste artigo foi a análise das percepções de discentes do $7^{\circ}$ ano do Ensino Fundamental II acerca da qualidade da água. Baseados no questionário aplicado, é possível afirmar que o conhecimento teórico dos alunos é insuficiente quando analisadas as questões que abordam partes mais específicas do assunto, como por exemplo a qualidade da água e possíveis doenças.

Quanto ao conhecimento popular, é possível verificar que há um conhecimento empírico, principalmente no que tange à distribuição, desperdício e dano ambiental, o que faz pensar que os professores de ciências aprofundam mais em perspectiva ambiental e sustentável do que nas propriedades e características químicas e biológicas do recurso natural.

Isso não deve ser visto como um ponto negativo, pois os próprios alunos compreendem ser necessária uma disciplina de educação ambiental para que tópicos como esse possam ser explanados de maneira convincente e ininterrupta. Isso porque o contexto interdisciplinar da educação ambiental é desenvolvido de forma frágil nos livros didáticos do ensino básico.

Em paralelo, destaca-se a importância de investimentos em metodologias ativas e experimentais no ensino de ciências, que sejam capazes de promover uma aprendizagem efetiva 
de assuntos aprofundados, possibilitando o progresso de um pensamento crítico, complexo e reflexivo quando associado às demais disciplinas, entre elas, a Educação Ambiental.

\section{Referências}

ANTUNES, C. M. M.; BITTENCOURT, S. C.; RECH, T. D.; OLIVEIRA, A. C. Qualidade das águas e percepção de moradores sobre um rio urbano. Revista Brasileira de Ciências Ambientais, Rio de Janeiro, n. 32, p. 75-87, 2014.

BRASIL. Secretaria de Educação Fundamental. Parâmetros curriculares nacionais: introdução aos parâmetros curriculares nacionais. Brasília: MEC/SEF, 1997. 126 p.

BRASIL. [Constituição (1988)]. Constituição da República Federativa do Brasil de 1988. Brasília, DF: Presidência da República, [2020]. Disponível em: http://www.planalto.gov.br/ccivil_03/constituicao/constituicao.htm. Acesso em: 21 maio 2019.

BRASIL. Lei No 12.651, de 25 de maio de 2012. Esta Lei estabelece normas gerais sobre a proteção da vegetação, áreas de Preservação Permanente e as áreas de Reserva Legal. Brasília, Presidência da República, 2012. Disponível em: http://www.planalto.gov.br/ccivil_03/_Ato2011-2014/2012/Lei/L12651.htm\#art83. Acesso em: 03 maio 2020.

CAMARGO, D. M.; SOUZA, N. M.; PACHECO, T. C. K. F.; ALCÂNTARA, G. C.; DOTA, E. M. Modelagem geoespacial para identificação de áreas vulneráveis ao contágio por doenças relacionadas à falta de saneamento: o caso da região metropolitana de Campinas.

Revista Brasileira de Cartografia, Monte Carmelo - MG, v. 69, n. 3, p. 561-573, 2017.

CONTINI, G.; PINTO, R.; BARROS, A. J. Diagnóstico das condições das nascentes na cidade de João Monlevade -MG: análise física e microbiológica. Revista Contribuciones a las Ciencias Sociales, Málaga, España, v. 6, p. 30-49, 2017.

DUARTE, M. S. B.; MENDONÇA, A. M. G. D.; PEREIRA, D. L.; RAMOS, A. M. C.; MENDONÇA, J. J. Estudo da qualidade da água como referência para educação ambiental do ensino de química. In: ENCONTRO NACIONAL DE EDUCAÇÃ̃, CIÊNCIA E TECNOLOGIA, 1., 2012, João Pessoa. Anais [...]. João Pessoa: UEPB, 2012. Disponível em: https://editorarealize.com.br/artigo/visualizar/1708. Acesso em: 03 maio 2020.

INSTITUTO TRATA BRASIL (Brasil). Manual do Saneamento Básico: Entendendo o saneamento ambiental no Brasil e sua importância socioeconômica. 2012. Disponível em: http://www.tratabrasil.org.br/datafiles/uploads/estudos/pesquisa16/manual-imprensa.pdf. Acesso em: 01 abr. 2020.

JACOBI, P. R. Educação ambiental: o desafio de um pensamento crítico, complexo e reflexivo. Educação e Pesquisa, São Paulo, v. 31, n. 2, p. 233-250, 2005.

LOUREIRO, C. F. B. Movimento de cidadania pelas águas do rio Paraíba do Sul. Rio de Janeiro: Instituto de Pesquisa Databrasil; Ministério do Meio Ambiente, 1997. Relatório de Pesquisa. 
OLIVEIRA, J. R. S. A Perspectiva socio-histórica de Vygotsky e suas relações com a prática da experimentação no ensino de Química. Revista de Educação em Ciências e Tecnologia, Florianópolis, v. 3, n. 3, p. 25-45, 2010.

OPARIN, A. I. The origin of life. 1924. Disponível em: https://www.valencia.edu/ orilife/textos/The\%20Origin\%20of\%20Life.pdf. Acesso em 03 maio 2020.

PICCOLI, A. S.; KLIGERMAN, D. C.; COHEN, S. M.; ASSUMPÇÃO, R. F. A educação ambiental como estratégia de mobilização social para o enfrentamento da escassez de água. Ciência e Saúde Coletiva, Rio de Janeiro, v. 21, n. 3, p. 797-808, 2016.

REBOUÇAS, A.C. Água doce no Mundo e no Brasil. In: REBOUÇAS, A.C. Águas doces no Brasil. 2. ed. São Paulo: Escrituras Editora, 2002. p. 1-37.

RÊGO, J. R. S.; LIMA, A. M. M. A percepção dos alunos do ensino fundamental sobre o uso da água consumida no município de Belém-PA. Revista Eletrônica do Mestrado em Educação Ambiental, Rio Grande - RS, v. 35, n. 2, p. 155-172, 2018.

ROSEN, G. A history of public health. New York: MD Publications, 1958. 551 p.

SPINELLI, M. V. P.; CARVALHO, R. M. C. M. O.; SILVA, H. P.; BRANDÃO, S. S. F.; FRUTUOSO, M. N. M. A. Estudo sustentável da capacidade de carga antrópica e a sua influência no ponto de equilíbrio da resiliência ambiental. Revista Brasileira de Geografia Física, Recife, v. 9, n. 1, p. 185-199, 2016.

TUNDISI, J. G. Água no século XXI: enfrentando a escassez. São Carlos: Rima/IIE, 2003. ISBN: 8586552518.

TUNDISI, J. G. Novas perspectivas para a gestão de recursos hídricos. Revista USP, São Paulo, n.70, p. 24-35, 2006.

VIEGAS, P. L; NEIMAN, Z. A Prática de educação ambiental no âmbito do ensino formal: estudos publicados em revistas acadêmicas brasileiras. Pesquisa em Educação Ambiental, Ribeirão Preto - SP, v. 10, n. 2, p.45-61, 2015. 